Human

Development
Psicologia: Teoria e Prática, 21(3), 405-417. São Paulo, SP, set.-dez. 2019. ISSN 1516-3687 (impresso), ISSN 1980-6906 (on-line). doi:10.5935/1980-6906/psicologia. V21n3p405-417. Sistema de avaliação: às cegas por pares (double blind review). Universidade Presbiteriana Mackenzie.

\title{
Current issues in epidemiogical studies of autism
}

\author{
Éric Fombonne ${ }^{1}$
}

(iD) https://orcid.org/0000-0002-8605-3538

To cite this paper: Fombonne, E. (2019). Current issues in epidemiogical studies of autism. Psicologia: Teoria e Prática, 21(3), 405-417. doi:10.5935/1980-6906/psicologia. v21n3p 405-417

Submission: 09/04/2019

Acceptance: 05/07/2019

1 Oregon Health and Science University, Portland, OR, USA. 


\begin{abstract}
Epidemiological surveys have increased in number and complexity. This paper focuses on a few selected issues that persist in the field of autism epidemiology today. Recent surveys have improved case ascertainment by including a regular school survey component, and they have consistently identified cases which were undiagnosed. However, the logistic of these surveys is complex, and the data analysis of these complex survey designs can lead to serious over- and sometimes under-estimation of overall population prevalence. Other issues discussed concern techniques used to confirm and validate caseness in surveys. Surveys relying on mechanical use of diagnostic algorithms or single questionnaire answers are plagued with measurement error. The impact of the repeated changes in nosographical systems and the recent changes of DSM- 5 are discussed. Issues specific to surveys of adults and preschoolers are briefly reviewed. Finally, contributions from international studies and the need for further cross-cultural comparisons are considered.
\end{abstract}

Keywords: Autism Spectrum Disorder; epidemiology; prevalence; methodology; global health.

\title{
ATUALIZAÇÕES EM EPIDEMIOLOGIA DO AUTISMO
}

\section{Resumo}

Os estudos epidemiológicos aumentaram em número e complexidade. Este artigo tem como foco alguns problemas que ainda persistem no campo da epidemiologia do autismo. As pesquisas mais recentes aprimoraram os métodos de averiguação de casos, principalmente incluindo coleta de dados em escolas regulares. Essa estratégia tem, consistentemente, permitido a identificação de casos que anteriormente ficavam sem diagnóstico. Entretanto, a logística dessas pesquisas é complexa e a análise de dados desses estudos pode levar a uma sobrestimação e, às vezes, a uma subestimação da prevalência global da população. Outra temática discutida neste artigo diz respeito às técnicas usadas para confirmar e validar pesquisas. Estudos baseados no uso mecânico de algoritmos ou em pontuação de um único questionário podem levar a erros de medição. O impacto das frequentes mudanças nos sistemas nosográficos e as recentes alterações no DSM- 5 são discutidas. Questões específicas para pesquisas com adultos e crianças são brevemente revisadas. Finalmente, são consideradas contribuições de estudos internacionais e a necessidade de mais comparações interculturais.

Palavras-chave: Transtorno do Espectro Autista; epidemiológico; prevalência; metodologia; saúde global. 


\section{ACTUALIZACIONES EN EPIDEMIOLOGÍA DEL AUTISMO}

\section{Resumen}

Estudios epidemiológicos han aumentado en número y complejidad. Este artículo se centra en problemas que persisten en el campo de la epidemiología del autismo. Investigaciones recientes han mejorado la detección de casos, incluido el componente de investigación en la escuela. Esto ha identificado casos que no fueron diagnosticados. Sin embargo, la logística de encuestas es compleja y el análisis de los datos puede llevar a sobreestimación o subestimación de la prevalencia de la populacion. Otros temas discutidos son las técnicas utilizadas para confirmar y validar la investigación. La pesquisa basada en el uso mecánico de algoritmos o cuestionario está plagada de errores de medición. Se discute el impacto de los cambios repetidos en los sistemas nosográficos y los cambios recientes en el DSM-5. Las preguntas para la investigación con adultos y niños se revisan brevemente. Se consideran las contribuciones de los estudios internacionales y la necesidad de más comparaciones interculturales.

Palabras clave: Trastorno del Espectro Autista; epidemiológico; prevalencia; metodologia; salud global.

\section{Introduction}

Since the first autism survey conducted in England in 1966, epidemiological surveys have increased in number and complexity. Contrasting with the first studies that were simple headcounts of children already diagnosed with a severe autism phenotype and residing in small, circumscribed geographical areas, current surveys now include large populations, multiple sites, stratified samples and rely on intricate sets of screening activities followed by some form of diagnostic confirmation procedures. However, there is no standardization of autism survey methodology, and as a result, differences in methodologies account for substantial heterogeneity in survey findings. Each survey has unique design features that reflect the local educational and health services infrastructure and current social policies for children with disabilities, include or not parents, teachers, and subjects with Autism Spectrum Disorder (ASD), and rely on variable screening and diagnostic instruments and methods. As such, prevalence differences between studies are hazardous to evaluate, and whether observed discrepancies are due to method factors or true differences in population parameters cannot be determined. In this brief article, we expand on the comments we made in a recent Editorial (Fombonne, 2018). 
Our goal was not to provide a comprehensive review of surveys that can be found elsewhere (Meyers, Chavez, Presmanes Hill, Zuckerman, \& Fombonne, 2019; McFarlane et al., 2019); rather, we focus on a few selected issues that persist in the field of autism epidemiology today.

\subsection{Case ascertainment}

Classically, surveys identified cases by zooming in on children already diagnosed with autism or other behavioral or developmental problems. This approach to case ascertainment did not permit researchers to identify cases without a previously recognized condition and resulted in imperfect sensitivity. The addition of a regular school survey component in recent surveys (Kim et al., 2011; Fombonne et al., 2016; Alshaban et al., 2019) and in new studies in China and South Carolina have addressed this concern. However, new issues arose with this approach. First, screening tools, such as the Social Responsiveness Scale, the Social Communication Questionnaire and others show only mediocre specificity, their cut-offs have not been well-calibrated for use in general population studies, and when both teachers and parents are used as informants, no clear rule exist for combining their often discrepant results. Second, and most importantly, is the relatively low participation (36\% to 63\%) to the initial screening and in other survey phases (e.g., participation to a diagnostic confirmation session). Statistical analyses of these complex survey designs were made adequate by applying a series of weights to account for different sampling fractions and participation rates at each survey phase. However, in doing so, strong, unchecked, assumptions had to be made as to whether participation was associated (or not) to caseness. In the complete absence of information about non-participants, the assumption that they do not differ from participants concerning the presence/ absence of autism is a guess rather than a tested proposition. Parents of children with autism have unusually high participation in surveys (Fombonne, 2003), making it plausible that non-participants have 'less' autism than participants. Differential participation in that direction may have biased prevalence estimates upwards, a possibility appropriately discussed by the Korean study by its authors and other commentators (Pantelis \& Kennedy, 2015). Conversely, prevalence can be underestimated if parents of children with ASD are less likely to participate.

The Table below summarizes data from the three surveys that added a normal school survey to their case ascertainment approach. As it can be seen, the 
school survey prevalence was never nil, confirming that screening normal school children allows identifying new cases that would otherwise have been missed in the classic methods relying on children already diagnosed with some form of disability. However, as explained above, the accuracy of the school component of the prevalence cannot be gauged fully. Moreover, the relative contribution of the school prevalence to the overall population prevalence ranges from $28 \%$ to $72 \%$ (see Table 1.1). It is probable that this variation reflects differences in school survey methodology across these studies, although it might also reflect true differences across populations in the proportion of diagnosed/undiagnosed children. Unfortunately, there is no way to test these competitive interpretations.

Table 1.1. The contribution of school surveys to overall prevalence estimates

\begin{tabular}{ccccc}
\hline Setting & Reference & $\begin{array}{c}\text { Overall } \\
\text { prevalence }\end{array}$ & $\begin{array}{c}\text { School } \\
\text { survey } \\
\text { prevalence }\end{array}$ & $\begin{array}{c}\% \text { of overall } \\
\text { prevalence due to } \\
\text { school survey }\end{array}$ \\
\hline South Korea & $\begin{array}{c}\text { Kim et al. } \\
\text { (2011) }\end{array}$ & $2.64 \%$ & $1.89 \%$ & $71.6 \%$ \\
\hline Qexico & $\begin{array}{c}\text { Fombonne et } \\
\text { al. (2016) }\end{array}$ & $0.89 \%$ & $0.50 \%$ & $57.5 \%$ \\
\hline & $\begin{array}{c}\text { Alshaban et } \\
\text { al. (2019) }\end{array}$ & $1.14 \%$ & $0.32 \%$ & $28.1 \%$ \\
\hline
\end{tabular}

The addition of normal schools to the samples surveyed in autism epidemiology was a logical improvement that has proven to be contributory. However, the methods used to screen and confirm cases in large samples of typically developing children need to be refined.

\subsection{Case definition and confirmation}

An important aspect of survey methodology is how caseness is defined and case status determined in each study. There is no uniform case definition across published studies. Some surveys use electronic records of diagnoses, some rely on an autism special education eligibility, some rely on endorsement by caregivers of a single questionnaire item, others perform in-person clinical assessments and many, if not most, use combinations of modalities. 
Several issues need to be considered. First, the terminology of 'meeting diagnostic criteria' does not magically guarantee the validity of caseness unless careful attention is paid to the quality of the data used to score these criteria and to how much clinical wisdom was infused into this process. The DSM/ICD algorithms for PDD or ASD should only be considered as guiding principles which can help organize the available information and provide final coherence to clinical data stemming from different data sources and informants. How data are collected, by whom, from which informants and using which methods, and how discrepancies between data sources are resolved are essential features to consider. Second, even when the ADI-R and ADOS are employed for in-person assessments, case status confirmation based on 'scoring above/below threshold' results are far from being sufficient. In reputable investigations (e.g., Lord 2012), scoring rules and cut-offs had to be bent and adjusted to increase the fit of these instruments to the observed phenotype. The validity of case status determination does not reside in any instrument or its scores; rather, it requires a higher-order, interpretative, process informed by expert clinical judgment. It is important to remember that even instruments like the ADI-R and the ADOS have been developed to be used in conjunction and that their results must be reviewed and interpreted by a clinical expert. Similarly, it ought to be remembered that diagnostic algorithms of the ICD and DSM have been validated against a gold standard that was the clinical judgment of experts (see for example Volkmar et al., 1994).

Third, diagnostic algorithms and ADI-R/ADOS cut-offs have been calibrated against control samples that have typically included participants with either typical development or intellectual disability without autism. The performance of these tools may be seriously challenged when applied to samples enriched with varied types of psychopathology. Moreover, epidemiological samples include school (rather than preschool) age subjects with language and intellectual skills within the normal range. At that age, many psychiatric disorders are associated with social-communication symptoms (e.g., peer relationship problems) and even restricted and repetitive behaviors (e.g., in OCD), allowing autism symptoms to be easily 'scored' and wrongly endorsed. In the absence of an experienced clinical evaluation, scoring criteria and mechanical reliance on algorithms, either from record reviews or diagnostic instruments, may easily be misleading. Fourth, surveys have incorporated in their case status definition ill-defined diagnostic subtypes, 
such as PDDNOS, whether ICD or DSM (up to recently) was used. Based on the presence of two diagnostic criteria (one social, one other) only, and no longer requiring evidence of abnormality before age three, contamination of case status with phenocopies of all kinds is a strong possibility. There again, false positives are more likely when mechanical rules devoid of clinical judgment are used to establish caseness. Fifth, screening and diagnostic confirmation should rely on reasonably independent procedures. If clinical record review is used as the main procedure to screen AND to confirm a diagnosis, the risk of circularity is very high. In the medical record of a child diagnosed with ASD or having an education autism eligibility, the documentation in the record will obviously contain descriptions supporting that classification, making it, in turn, difficult to truly evaluate its validity. CDC surveys are particularly vulnerable to this problem. Finally, surveys using large nationally representative samples, such as the US National Health of Children Survey, have yielded prevalence estimates relying on highly problematic caseness determination. Gains in sample representativeness were mitigated by reliance on simple yes/no answers by household informants to one or a few survey questions ("Did a doctor or health professional ever tell you that [child's name] had autism, Asperger's disorder, pervasive developmental disorder, or autism spectrum disorder?") to establish caseness (Kogan et al., 2018). Non-clinically trained interviewers recorded verbatim answers from respondents without further checking, children were not seen, and additional diagnostic evaluation reports were not collected. To illustrate further the limitations of this type of survey, a study by Zablotsky et al. (2015) showed that changes in the wording, format, and placement of the single autism question in the National Health Interview Survey resulted in a sharp prevalence increase from $1.25 \%$ in 2011 to $2.24 \%$ in 2014 , a difference seen as arising purely from questionnaire design modifications.

The repeated changes in nosographical systems create another source of measurement uncertainty in autism studies in general. There was relatively strong parallelism between ICD-10 and DSM-IV that was unfortunately lost with the recent changes in DSM 5. Nevertheless, the new, single, unified concept of Autism Spectrum Disorder (ASD) that replaces the previous umbrella diagnostic class of Pervasive Developmental Disorder (PDD) has increased specificity that should benefit epidemiological research. Preliminary studies comparing the effects of using DSM-IV or DSM 5 on prevalence estimates have shown that, with everything being 
equal, otherwise, the shift from DSM-IV to DSM 5 leads to a decrease of 13 to $20 \%$ in prevalence (Kim et al., 2014; Maenner et al., 2014). The decrease in prevalence is largely due to subjects with a DSM-IV diagnosis of PDD-NOS not meeting ASD criteria in DSM 5 (37\% decrease in Kim et al., 2014). Likewise, in the recent CDC survey of children age 8 (Baio et al., 2018), the prevalence of DSM 5 was $18.1 \%$ lower compared to that of DSM-IV-TR.

The defunct PDD-NOS will not be missed. It was an ill-defined diagnostic category with a poor inter-rater agreement. In a review of previous surveys (Fombonne, 2003), we noted that the proportion of PDDNOS diagnosed in epidemiological surveys was highly variable, accounting anywhere between $20 \%$ to $70 \%$ of the spectrum diagnoses reached in surveys. In addition, as narrated by Volkmar et al. (2000), a printing mistake in the 1994 DSM-IV manual initially enforced an hyperlax definition of PDD-NOS (one social OR communication criterion was sufficient) that was subsequently corrected (one social AND one communication criteria now required) in the DSM-IV-TR Edition (APA, 2000). The fact that in CDC surveys the proportion of PDDNOS diagnoses has revolved around $40 \%$ of the caseload adds further challenges to the interpretation of CDC surveys results (Fombonne, 2018).

\subsection{Specific populations}

Surveys have generally focused on school-age children. There are reasons why this is a good sampling choice. By the age of 8 , diagnoses can be verified and validated with robust instruments and methods. At lower ages, some children will be missed since the age of diagnosis is often delayed up to primary school entry. At older ages, some improvements in milder forms of the autism phenotype can pose difficulties for diagnostic confirmation. More importantly, a reason to focus on primary school age is that, in most countries, school attendance is compulsory after the age of six, which allows comprehensive sampling frames to be used by survey researchers.

Recently, some surveys have focused on younger children with some success. In a Vietnamese study, Hoang et al. (2019) reported a prevalence of $0.75 \%$ among 17 recently, 277 children aged 18 to 30 months screened with the M-CHAT and followed-up with diagnostic assessments. Surprisingly, the authors reported prevalences of $0.77 \%$ in $18-23$ months old and of $0.74 \%$ among $24-30$ months old; this finding is atypical as one would expect the prevalence to be much higher in older children. Survey data were not weighted appropriately based on the screen- 
ing phase results, which make the results difficult to interpret. The CDC released recently first prevalence estimates for the US population of children age four surveyed in 2010, 2012, and 2014 (Christensen et al., 2019). As for surveys among older children, there was a huge variability across site-specific estimates that ranged from $0.81 \%$ (Missouri, 2012) to $2.84 \%$ (New Jersey, 2014), a 3.5 fold variation. Overall, the prevalence was $1.70 \%$ for DSM-IV based definition, $20 \%$ higher than the $1.41 \%$ estimate derived from DSM 5. Considering that the average age at diagnosis in the US is around 48 months, these high figures among 4 -year olds are puzzling. The methodology employed was based on record review methodology that has limitations described in details elsewhere (Fombonne, 2018; Mandell and Lecavalier, 2014).

Inclusion of preschoolers in epidemiological surveys poses special challenges for complete case ascertainment. The screening tools currently available have limited sensitivity and specificity. To limit bias in prevalence estimation, it would be useful that future studies incorporate comprehensive longitudinal follow-up of preschool samples; however, the associated costs may be difficult to support by research teams and surveillance programs.

Adult surveys have been scarce. One exception is the studies performed in England on combined samples of adults living in typical households or in accommodations for adults with intellectual disabilities (ID) (Brugha et al., 2016). These authors reported a prevalence of $1.1 \%$ with no variation across different age bands. The prevalence was much higher in the subsample with moderate to severe ID that also had a low male: female ratio compared to the usual male preponderance found in the sample without ID. This survey piloted a thoughtful adult survey methodology (Brugha et al., 2012). Limitations were a low participation rate in the subsample with ID, and the small number of affected adults among those without ID. There is no doubt that more surveys of adults with ASD are necessary, not only to estimate the prevalence or track time trends, but in order to identify unmet service needs of this growing fraction of the population.

\subsection{International studies}

The last 20 years have seen a welcome expansion of epidemiological surveys of child populations worldwide. In many countries, lack of awareness and of diagnostic and intervention expertise persist with negative social stigmatization. How- 
ever, with the development of the internet and social media, and of advocacy organizations, it has become more difficult for governments to ignore the individual, familial and societal problems associated with autism and neurodevelopmental disorders in general. Epidemiological surveys are a natural starting point for developing research expertise on these conditions; governments and their decision-making agencies need local, quantitative data to guide their service planning decisions. Everywhere it has been studied, autism has been found; and when survey methods have been appropriate, the prevalence in the neighborhood of $1 \%$ has been reported in countries as diverse as India, Qatar, Mexico or China. There is no evidence that there are countries either very low or very high in their autism rate. Several countries are now considering the implementation of national registries or surveillance programs that will help track the incidence of ASD in their populations in the future.

In conducting studies in varied cultural settings, I have remarked upon the similarity of the autism phenotype and its clinical presentations across societies and cultures. Of course, some cultural adaptations of our tools have been necessary here and there. In China, the birthday party task of the ADOS Module 1 needed to be replaced by an equivalent task since birthday parties are not part of the familial traditions. In South Africa, the screwdriver toy of the Toddler ADOS needed to be removed in townships where these tools are commonly associated with violence and murder. In several Asian countries, eye contact from children to adults is discouraged, and rules for appropriate social behavior emphasize compliance in children. In turn, these cultural features may require an adjustment in our professional definition and evaluation of reciprocity in social interactions. Fifteen years ago, I was adapting a version of the Social Communication Questionnaire in Inuktitut to use as a screening tool in my work with Inuit communities of Northern Canada, only to discover that, to mean 'No' or 'Yes,' frowning the nose or raising the eyebrows are substituted to the conventional shaking and nodding the head. These observations call for appropriate cultural sensitivity in working across cultures and may necessitate the occasional change in questionnaire item wordings or testing apparatus. These examples are anecdotal, and a systematic investigation of differences in the measurement of the autism phenotype across cultures remains to be done.

Cross-cultural comparisons have been performed in other areas of psychopathology, e.g., the WHO world studies of schizophrenia in the 1970s, the US-UK 
comparisons of ADHD diagnostic approaches in the 1980s, and more recently, the cross-national comparative analyses of the Child Behavior Checklist. Investigators who are embarking in autism surveys should keep in mind that their research data could be leveraged by embarking into international collaborations set to more systematically test the transcultural robustness of the autism phenotype and of its measurement.

\section{References}

Alshaban, F., Aldosari, M., Al-Shammari, H., El-Hag, S., Ghazal, I., Tolefat, M., ... Fombonne, E. (2019). Prevalence and correlates of autism spectrum disorder in Qatar: A national study. Journal of Child Psychology and Psychiatry. doi:10.1111/jcpp.13066

American Psychiatric Association (1994). Diagnostic and Statistical Manual of Mental Disorders (4th ed.). Washington, DC: American Psychiatric Association.

American Psychiatric Association (Ed.). (2000). Diagnostic and statistical manual of mental disorders: DSM-IV-TR (4th ed., text revision). Washington, DC: American Psychiatric Association.

American Psychiatric Association (Ed.). (2013). Diagnostic and statistical manual of mental disorders: DSM-5 (5th ed). Washington, D.C: American Psychiatric Association.

Baio, J., Wiggins, L., Christensen, D. L., Maenner, M. J., Daniels, J., Warren, Z., ... Dowling, N. F. (2018). Prevalence of Autism Spectrum Disorder Among Children Aged 8 Years - Autism and Developmental Disabilities Monitoring Network,11 Sites, United States, 2014. MMWR Surveill Summ, 67(6), 1-23. doi:10.15585/mmwr.ss6706a1

Brugha, T. S., Spiers, N., Bankart, J., Cooper, S. A., McManus, S., Scott, F. J., ... Tyrer, F. (2016). Epidemiology of autism in adults across age groups and ability levels. British Journal of Psychiatry, 209(6), 498-503. doi:10.1192/bjp.bp.115.174649

Brugha, T. S., McManus, S., Smith, J., Scott, F. J., Meltzer, H., Purdon, S., ... Bankart, J. (2012). Validating two survey methods for identifyingcases of autism spectrum disorderamong adults in the community. Psychological Medicine, 42(3), 647-656. doi:10.1017/So033291711001292

Christensen, D. L., Maenner, M. J., Bilder, D., Constantino, J. N., Daniels, J., Durkin, M. S., \& Dietz, P. (2019). Prevalence and Characteristics of Autism Spectrum Disorder Among Children Aged 4 Years - Early Autism and Developmental Disabilities Monitoring Network, Seven Sites, United States, 2010, 2012, and 2014. MMWR. Surveillance Summaries, 68(2), 1-19. doi:http://dx.doi.org/10.15585/mmwr.ss6802a1 
Fombonne, E. (2003). Epidemiological surveys of autism and other pervasive developmental disorders: an update. Journal of Autism and Developmental Disorders, $33(4), 365-381$.

Fombonne, E. (2018). Editorial: The rising prevalence of autism. Journal of Child Psychology and Psychiatry, 59(7), 717-720. doi:10.1111/jcpp.12941

Fombonne, E., Marcin, C., Manero, A. C., Bruno, R., Diaz, C., Villalobos, M., ... Nealy, B. (2016). Prevalence of Autism Spectrum Disorders in Guanajuato, Mexico: The Leon survey. Journal of Autism Developmental Disorders, 46(5), 1669-1685. doi:10.1007/ s10803-016-2696-6

Hoang, V. M., Le, T. V., Chu, T. T. Q., Le, B. N., Duong, M. D., Thanh, N. M., ... Bui, T. T. $\mathrm{H}$. (2019). Prevalence of autism spectrum disorders and their relation to selectedsocio-demographic factors among children aged 18-30 months in northern Vietnam, 2017. International Journal of Mental Health Systems, 13(29). doi:10.1186/ s13033-019-0285-8

Kim, Y. S., Leventhal, B. L., Koh, Y. J., Fombonne, E., Laska, E., Lim, E. C., ... Grinker, R. R. (2011) Prevalence of Autism Spectrum Disorder in a Total Population Sample. American Journal of Psychiatry, 168(9), 904-912. doi:10.1176/appi.ajp.2011.10101532

Kim, Y. S., Fombonne, E., Koh, Y.-J., Kim, S.-J., Cheon, K.-A., \& Leventhal, B. L. (2014). A comparison of DSM-IV pervasive developmental disorder and DSM- 5 autism spectrum disorder prevalence in an epidemiologic sample. Journal of the American Academy of Child and Adolescent Psychiatry, 53(5), 500-508. doi:10.1016/j.jaac.2013.12.021

Kogan, M. D., Vladutiu, C. J., Schieve, L. A., Ghandour, R. M., Blumberg, S. J., Zablotsky, B., ... Lu, M. C. (2018). The Prevalence of Parent-Reported Autism Spectrum Disorder Among US Children. Pediatrics, 142(6). doi:10.1542/peds.2017-4161

Lord, C., Petkova, E., Hus, V., Gan, W., Lu, F., Martin, D. M., ... Risi, S. (2012). A Multisite Study of the Clinical Diagnosis of Different Autism Spectrum Disorders. Archives Of General Psychiatry, 69(3), 306-313. doi:10.1001/archgenpsychiatry.2011.148

Maenner, M. J., Rice, C. E., Arneson, C. L., Cunniff, C., Schieve, L. A., Carpenter, L. A., ... Durkin, M. S. (2014). Potential impact of DSM-5criteria on autism spectrum disorder prevalence estimates. JAMA Psychiatry, 71(3), 292-300. doi:10.1001/ jamapsychiatry.2013.3893

Mandell, D., \& Lecavalier, L. (2014). Should we believe the Centers for Disease Control and Prevention's autism spectrum disorder prevalence estimates? Autism, 18(5), 482-484. doi:10.1177/1362361314538131 
Meyers, J., Chavez, A., Presmanes Hill, A., Zuckerman, K., \& Fombonne, E. (2019). Epidemiological Surveys of Autism Spectrum Disorders. In F. Volkmar (Ed.), Autism and Pervasive Developmental Disorders. 2nd Edition. Cambridge: Cambridge University Press.

McFarlane, H., Salem, A., Lawley, G., Presmanes Hill, A., Zuckerman, K., \& Fombonne, E. (2019 in press). Epidemiology. In Edited E. Hollander, R. Hagerman, and C. J. Ferretti (Ed.), Autism Spectrum Disorders. $2^{\text {nd }}$ Edition. Washington, DC: American Psychiatric Association Publishing.

Pantelis, P. C., \& Kennedy, D. P. (2015). Estimation of the prevalence of autism spectrum disorderinSouthKorea, revisited.Autism,20(5),517-527.doi:10.1177/1362361315592378

Volkmar, F. R., Klin, A., Siegel, B., Szatmari, P., Lord, C., Campbell, M., ... Kline, W. (1994). Field trial for autistic disorder in DSM-IV. The American Journal of Psychiatry, 151(9), 1361-1367.

Volkmar, F. R., \& Shaffer, D. (2000). First M. PDDNOS in DSM-IV. Journal of Autism and Developmental Disorders, 30(1), 74-75.

World Health Organization (1992). International Statistical Classification of Diseases and Related Health Problems (10th Revision). Geneva: World Health Organization.

Zablotsky, B., Black, L., Maenner, M. J., Schieve, L. A., \& Blumberg, S. J. (2015). Estimated Prevalence of Autism and Other Developmental Disabilities Following Questionnaire Changes in the 2014 National Health Interview Survey. National Health Statistics Reports, (87), 1-20.

\section{Authors notes}

Éric Fombonne, Department of Psychiatry, Institute for Development \& Disability, Oregon Health and Science University (OHSU).

Correspondence concerning this article should be addressed to Éric Fombonne, OHSU Institute on Development and Disability, Child Development and Rehabilitation Center, 707 S.W. Gaines Street, Portland, OR, USA. 97239.

E-mail: fombonne@ohsu.edu 